\title{
NOVAS MÉTRICAS HOLÍSTICAS PARA AVALIAÇÃO DA VERDURA DE REAÇÕES DE SÍNTESE EM LABORATÓRIO
}

\author{
Maria Gabriela T. C. Ribeiro* \\ REQUIMTE, Departamento de Química e Bioquímica, Faculdade de Ciências, Universidade do Porto, Rua do Campo Alegre, \\ 687, Porto 4169-007, Portugal \\ Adélio A. S. C. Machado \\ Departamento de Química e Bioquímica, Faculdade de Ciências, Universidade do Porto, Rua do Campo Alegre, 687, Porto \\ 4169-007, Portugal
}

Recebido em 29/11/11; aceito em 16/5/12; publicado na web em 24/8/12

\begin{abstract}
NEW HOLISTIC METRICS FOR ASSESSING GREENNESS OF CHEMICAL REACTIONS IN THE LABORATORY. New semi-quantitative metrics for simple evaluation of global greenness of chemical reactions used in teaching laboratories, namely, the Green Circle (GC) and Green Matrix (GM), were developed. These metrics globally consider all Twelve Principles of Green Chemistry. To illustrate their construction, the greenness of several syntheses performed in the laboratory under different sets of conditions was assessed. The tools were validated by comparing the results with another metric, the Green Star (GS), developed in our previous study. Results showed these new metrics were useful for the intended purpose, having the advantage of being simpler than the GS.
\end{abstract}

Keywords: green metrics; reaction greenness improvement; green chemistry education.

\section{INTRODUÇÃO}

A verdura química, algo elusivo mas fulcral em Química Verde (QV), é um conceito de difícil avaliação devido à complexidade intrínseca da Química e das suas múltiplas relações com o ambiente, a biosfera e a sociedade. As métricas de massa da QV fornecem indicações úteis sobre a verdura, mas têm um alcance limitado pois aferem apenas a produtividade atómica; em consequência, fornecem uma avaliação incompleta do grau de verdura, que não toma em consideração os riscos para a saúde e para o ambiente - além de que, em alguns casos, os seus resultados podem ser contraditórios. ${ }^{1-3}$ As métricas ambientais ${ }^{4,5}$ são por isso um complemento essencial da avaliação da verdura, mas são complexas e difíceis de usar. Para obviar ao uso de conjuntos numerosos de métricas é preferível usar métricas holísticas, embora estas sejam difíceis de construir e, por vezes, de usar. Em trabalho anterior, desenvolvemos uma métrica deste tipo, a Estrela Verde (EV), ${ }^{1-3}$ que atende simultaneamente aos 12 princípios da $\mathrm{QV}^{6}$ que sejam aplicáveis à situação em avaliação (reação química, processo químico, etc.) e tem como objetivo ser uma métrica sistémica de benignidade intrínseca. Os resultados obtidos na sua aplicação em situações diversas ${ }^{1-3,7,8}$ demostraram a utilidade da sua abordagem holística para avaliar a verdura, mas situações houve em que a utilização da EV se mostrou bastante trabalhosa. Por isso, surgiu a ideia de construir outras métricas holísticas que também cobrissem todos os princípios aplicáveis em cada situação sob estudo, mas que fossem de implementação mais simples do que a EV.

Este artigo tem como objetivo apresentar dois processos semiquantitativos de avaliação da verdura construídos neste contexto, o Círculo Verde (CV) e a Matriz Verde (MV). ${ }^{9}$ Estas ferramentas têm por base a análise do cumprimento individual dos 12 princípios da QV a partir de critérios previamente definidos, sendo os resultados da avaliação apresentados em gráficos circulares construídos em folhas de cálculo Excel (CV, em que os critérios de decisão são do tipo binário - cumprimento/não cumprimento de cada princípio)

*e-mail: gribeiro@fc.up.pt ou em tabelas (MV, obtida por uma análise $\mathrm{SWOT}^{10}$ ). Os processos foram testados numa série de sínteses cuja verdura foi anteriormente analisada e otimizada por meio da $\mathrm{EV}^{3}{ }^{3}$ com vista a aferir a qualidade da avaliação conseguida e proporcionar informação sobre as vantagens e desvantagens destas novas métricas sobre aquela. $\mathrm{Na}$ Figura 1 resume-se graficamente o alcance, objetivos e estratégia do trabalho realizado.

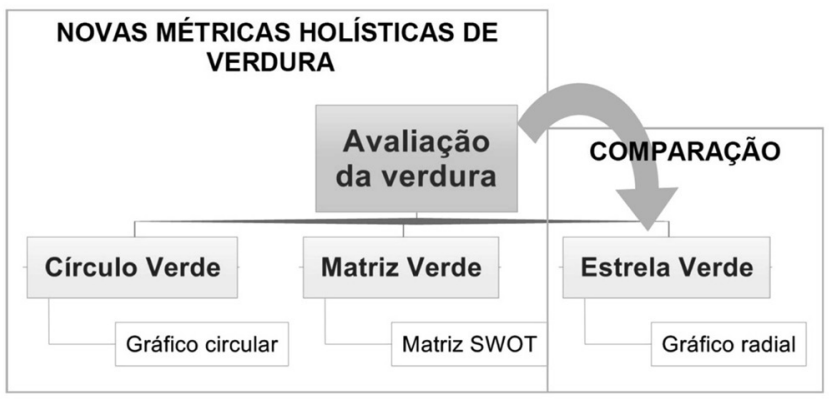

Figura 1. Métricas de avaliação holística da verdura

\section{CONSTRUÇÃO DAS MÉTRICAS}

Quando se pretende realizar uma avaliação de verdura enquadrada pelos 12 princípios da QV, é necessário começar por definir quais os princípios que são relevantes para o estudo em causa. Considerando que neste artigo são avaliadas sínteses realizadas em laboratório, num contexto do ensino da Química, os quarto e décimo primeiro princípios foram excluídos, já que no ensino não se costuma realizar a conceção de novos produtos químicos, à qual eles se aplicam.

Para proceder à avaliação é necessário analisar previamente os protocolos das sínteses relativamente às condições de pressão e temperatura a que se realizam, averiguar se se usam reagentes estequiométricos em excesso e inventariar todas as substâncias envolvidas: reagentes, produtos e coprodutos obtidos, catalisadores, solventes, agentes de purificação, secantes e resíduos formados. Para 
todas essas substâncias é necessário recolher informação acerca dos riscos para a saúde e para o ambiente, inflamabilidade e reatividade e, ainda, se constituem ou são obtidas de matérias-primas renováveis, e se são degradáveis a produtos de degradação inócuos. Essas informações, nos casos apresentados a seguir, foram obtidas das fichas de dados de segurança de produtos químicos (MSDS). $\mathrm{Na}$ Tabela 1 são definidos os critérios para considerar se cada um dos princípios é cumprido e na Tabela 2 os critérios para avaliar os riscos para a saúde, ambiente e de acidente químico devido às substâncias envolvidas, usados na avaliação do cumprimento dos princípios P1, P3, P5, P9 e P12.

Tabela 1. Critérios para avaliação do cumprimento dos princípios da QV

\begin{tabular}{ll}
\hline Princípio da QV & Critérios \\
\hline P1 - Prevenção & $\begin{array}{l}\text { Não se formam resíduos, ou quando se for- } \\
\text { mam têm riscos baixos para a saúde e para } \\
\text { o ambiente }\end{array}$ \\
\hline
\end{tabular}

\begin{tabular}{ll}
\hline P2 - Economia atómica & $\begin{array}{l}\text { Reações sem reagentes em excesso }(\leq 10 \%) \\
\text { e sem formação de coprodutos (não se con- } \\
\text { sidera a água) }\end{array}$ \\
\hline
\end{tabular}

P3 - Sínteses menos perigosas Todas as substâncias envolvidas são inócuas ou têm riscos baixos para a saúde e para o ambiente

P5 - Solventes e outras subs- Não se utilizam solventes nem outras substâncias auxiliares mais seguras tâncias auxiliares, ou quando se utilizam têm riscos baixos para a saúde e para o ambiente

P6 - Planificação para conse- Pressão e temperatura ambientais guir eficácia energética

P7 - Uso de matérias primas Todos os reagentes/matérias-primas envolvirenováveis dos são renováveis

P8 - Redução de derivatizações Não se utilizam derivatizações

P9-Catalisadores Catalisadores não necessários ou que têm riscos baixos para a saúde e para o ambiente

P10 - Planificação para a de- Todas as substânsias envolvidas são gradação degradáveis com os produtos de degradação inócuos

P12 - Química inerentemente As substâncias envolvidas têm um risco baixo mais segura quanto à prevenção de acidente químico

de acidentes

\section{Círculo verde}

Esta métrica gráfica consiste num círculo dividido em tantos setores quantos os princípios avaliados, coloridos de cinza claro ou cinza escuro nas figuras a preto e branco deste texto (ou verde e amarelo na versão eletrónica) conforme os respetivos princípios são ou não cumpridos, segundo os critérios apresentados na Tabela 1.

A apreciação desta métrica, feita visualmente, é muito simples: quanto mais claro for o círculo, mais verde é a reação ou o processo avaliado. É ainda possível associar um Índice de Cumprimento dos Princípios (ICP) calculado como a percentagem de princípios cumpridos (100 x número de princípios cumpridos/número total de princípios que se aplicam). Quando todos os princípios são cumpridos $\mathrm{ICP}=100$, quando nenhum é, $\mathrm{ICP}=0$.

\section{Matriz verde (análise SWOT)}

Esta métrica baseia-se na análise SWOT para avaliação de cumprimento de objetivos previamente definidos. A análise SWOT surgiu nos anos sessenta na Harvard Business School, EUA, aplicada à avaliação empresarial, mas depois passou a ser usada em outros
Tabela 2. Critérios para avaliação dos riscos para a saúde, ambiente e de acidente químico devido às substâncias envolvidas

\begin{tabular}{|c|c|c|}
\hline \multicolumn{3}{|c|}{ Riscos para a saúde e ambiente devido às substâncias envolvidas } \\
\hline Riscos & Símbolos de risco & Classificação \\
\hline \multirow{3}{*}{ Saúde } & $\begin{array}{c}\mathrm{C}-\text { corrosivo } \\
\mathrm{T}-\text { tóxico } \\
\mathrm{T}+- \text { muito tóxico }\end{array}$ & elevado \\
\hline & $\begin{array}{l}\mathrm{Xn}-\text { prejudicial } \\
\mathrm{Xi}-\text { irritante }\end{array}$ & moderado \\
\hline & Nenhuma indicação & baixo \\
\hline \multirow{2}{*}{ Ambiente } & $\mathrm{N}$ - perigoso para o ambiente & elevado \\
\hline & Nenhuma indicação & baixo \\
\hline \multicolumn{3}{|c|}{ Riscos de acidente químico devido às substâncias envolvidas } \\
\hline Riscos & Símbolos de risco & Classificação \\
\hline \multirow{3}{*}{ Saúde } & $\begin{array}{c}\mathrm{C}-\text { corrosivo } \\
\mathrm{T}-\text { tóxico } \\
\mathrm{T}+- \text { muito tóxico }\end{array}$ & elevado \\
\hline & $\begin{array}{c}\mathrm{Xi}-\text { irritante } \\
\mathrm{Xn}-\text { prejudicial }\end{array}$ & moderado \\
\hline & Nenhuma indicação & baixo \\
\hline \multirow[t]{2}{*}{ Inflamabilidade } & $\begin{array}{c}\mathrm{F}-\text { muito inflamável } \\
\mathrm{F}+- \text { extremamente inflamável }\end{array}$ & elevado \\
\hline & Nenhuma indicação & baixo \\
\hline \multirow{3}{*}{ Reatividade } & E- explosivo & elevado \\
\hline & $\mathrm{O}$ - agente oxidante & elevado \\
\hline & Nenhuma indicação & baixo \\
\hline
\end{tabular}

campos, nomeadamente, mais recentemente, no domínio da tecnologia ${ }^{11}$ e da Química. ${ }^{9}$ Caracteriza-se pela identificação de pontos fortes e fracos do objeto em análise, que indicam os aspetos positivos e negativos, respetivamente, relativamente aos objetivos a atingir, definidos à partida. $\mathrm{O}$ conjunto dos pontos fortes e fracos corresponde à análise interna. É também efetuada uma análise externa, em que são analisadas as implicações de imposições externas ao objeto, que permite identificar as oportunidades (que podem tornar o objeto em análise mais forte) e as ameaças (que podem comprometer o sucesso dos objetivos estabelecidos). O termo SWOT resulta das iniciais $\mathrm{S}$ (Strenghts - pontos fortes), W (Weaknenesses - pontos fracos), O (Opportunities - oportunidades) e T (Threats - ameaças). Após definidos os objetivos, identificam-se os pontos fortes e fracos e as oportunidades e ameaças que se colocam ao cumprimento desses objetivos. Os resultados são apresentados em quadros designados matrizes SWOT (designadas aqui por Matrizes Verdes). No caso presente, os objetos em análise são as sínteses de compostos e o objetivo da análise é avaliar a verdura, aferida através do cumprimento dos 12 princípios da QV. Atendendo a que, neste caso, os resultados da análise explicitam os aspetos que podem permitir (pontos fortes) ou impedir (pontos fracos) o cumprimento de cada princípio, bem como ações que podem levar ao cumprimento dos princípios não ou deficientemente cumpridos (oportunidades) ou a dificultar esse cumprimento (ameaças), é necessário definir dimensões de análise relativamente às análises interna e externa.

\section{Análise interna}

Para esta análise foram definidas 10 dimensões de análise (têm por base os critérios de cumprimento dos princípios, definidos na Tabela 1) que se apresentam na Tabela 3, bem como os pontos fortes e fracos correspondentes a cada dimensão (os números atribuídos às 
Tabela 3. Dimensões de análise interna e critérios para a contabilização dos pontos fortes e fracos

\begin{tabular}{|c|c|c|}
\hline Dimensões de análise & Ponto Forte & Ponto fraco \\
\hline 1 - Riscos para a saúde e ambiente dos resíduos & $\begin{array}{l}\text { Não há formação de resíduos ou os resíduos têm } \\
\text { riscos baixos para a saúde e ambiente }\end{array}$ & $\begin{array}{l}\text { Há formação de resíduos com riscos moderados/ } \\
\text { elevados para a saúde e/ou ambiente }\end{array}$ \\
\hline $\begin{array}{l}\text { - Excesso de reagentes e formação de coprodutos } \\
\text { não se considera a água) }\end{array}$ & $\begin{array}{l}\text { Excesso de reagentes } \leq 10 \% \text { e não há formação de } \\
\text { coprodutos (a água não é considerada) }\end{array}$ & $\begin{array}{l}\text { Excesso de reagentes }>10 \% \text { e/ou há formação de } \\
\text { coprodutos }\end{array}$ \\
\hline $\begin{array}{l}\text { - Riscos para a saúde e ambiente devido às subs- } \\
\text { ancias envolvidas }\end{array}$ & $\begin{array}{l}\text { As substâncias envolvidas têm riscos baixos para } \\
\text { a saúde e ambiente }\end{array}$ & $\begin{array}{l}\text { As substâncias envolvidas têm riscos moderados/ } \\
\text { elevados para a saúde e/ou ambiente }\end{array}$ \\
\hline $\begin{array}{l}\text { ente dos solventes e/ } \\
\text { ares }\end{array}$ & $\begin{array}{l}\text { Não se utilizam solventes nem outras substâncias } \\
\text { auxiliares ou utilizam-se mas têm riscos baixos para } \\
\text { a saúde e ambiente }\end{array}$ & $\begin{array}{l}\text { Utilizam-se solventes e/ou outras substâncias auxili- } \\
\text { ares com riscos moderados/elevados para a saúde e/ } \\
\text { ou ambiente }\end{array}$ \\
\hline - Pressão e temperatura & Pressão e temperatura ambientais & Pressão ou temperatura diferentes da ambiental \\
\hline $\begin{array}{l}\text { - Utilização de substâncias renováveis (a água não } \\
\text { contabilizada) }\end{array}$ & $\begin{array}{l}\text { Todos os reagentes/matérias-primas envolvidos são } \\
\text { renováveis (a água não é considerada) }\end{array}$ & $\begin{array}{l}\text { Pelo menos um dos reagentes/matérias-primas não } \\
\text { é renovável (a água não é considerada) }\end{array}$ \\
\hline 3 - Derivatizações & Não se utilizam & Utilizam-se \\
\hline 9 - Utilização de catalizadores & $\begin{array}{l}\text { Catalizadores não necessários ou têm riscos baixos } \\
\text { para a saúde e ambiente }\end{array}$ & $\begin{array}{l}\text { Utilizam-se catalizadores com riscos moderados/ } \\
\text { elevados para a saúde e/ou ambiente }\end{array}$ \\
\hline $\begin{array}{l}10 \text { - Utilização de substâncias degradáveis a produtos } \\
\text { inócuos (a água não é contabilizada) }\end{array}$ & $\begin{array}{l}\text { Todas as substâncias envolvidas são degradáveis a } \\
\text { produtos inócuos (a água não é considerada) }\end{array}$ & $\begin{array}{l}\text { Pelo menos uma das as substâncias envolvidas } \\
\text { não é degradável a produtos inócuos (a água não é } \\
\text { considerada) }\end{array}$ \\
\hline $\begin{array}{l}12 \text { - Riscos de acidente químico devido às substâncias } \\
\text { envolvidas }\end{array}$ & $\begin{array}{l}\text { As substâncias envolvidas têm riscos baixos de } \\
\text { acidente químico }\end{array}$ & $\begin{array}{l}\text { As substâncias envolvidas têm riscos moderados/ } \\
\text { elevados de acidente químico }\end{array}$ \\
\hline
\end{tabular}

dimensões de análise correspondem ao princípio a que dizem respeito). A um princípio cumprido corresponderá, na análise, um ponto forte. Serão cumpridos tantos princípios quantos os pontos fortes e, quanto maior for o número de pontos fortes, maior é a verdura dos objetos em análise. Só alterações no objeto em análise, isto é, no presente caso, revisões no processo de síntese do composto que permitam a eliminação dos pontos fracos, e consequente aumento do número de pontos fortes, podem levar ao cumprimento dos princípios não cumpridos.

\section{Análise externa}

Para a definição das dimensões de análise externa tomaram-se em consideração, para as oportunidades, aspetos que podem levar ao cumprimento dos princípios não cumpridos (por eliminação dos pontos fracos e aumento dos pontos fortes); para as ameaças, condicionamentos externos que podem criar dificuldades às melhorias necessárias para que os princípios sejam cumpridos. Na Tabela 4 apresentam-se estas dimensões de análise.

\section{Leitura da verdura na $M V$}

Nas MV são elencados todos os pontos fortes e fracos, identificados de acordo com a Tabela 3. Os pontos fortes correspondem aos princípios cumpridos e os pontos fracos aos princípios não cumpridos. A MV será tanto mais verde quanto mais elevado for o número de pontos fortes (logo os princípios cumpridos). Os pontos fracos indicam quais os aspectos que impedem que os princípios a que se referem sejam cumpridos. Nas MV são também elencadas as oportunidades identificadas (de acordo com as dimensões estabelecidas na Tabela 4), que podem permitir aumentar o número de princípios cumpridos, logo aumentar a verdura da MV, não esquecendo dificuldades (ameaças) que se podem colocar à concretização dos aspetos referidos, impedindo a melhoria da verdura.

\section{Sínteses avaliadas}

Para ilustrar a utilização destas métricas apresentam-se as avaliações de sínteses de (tris)acetilacetonatos de ferro(III) e de (bis) acetilacetonatos de manganés(II) e de cálcio (usaram-se os resultados referentes a um conjunto de experiências realizadas em laboratório,
Tabela 4. Dimensões de análise externa

\begin{tabular}{ll}
\hline Oportunidades & Ameaças \\
\hline - Substituir as substâncias com riscos & - Dificuldades de realização nas con- \\
moderados/elevados por substâncias & $\begin{array}{l}\text { dições referidas nas oportunidades } \\
\text { por razões económicas ou por não } \\
\text { com riscos baixos }\end{array}$ \\
& existirem alternativas conhecidas
\end{tabular}

- Eliminar o uso de solventes ou substituir os solventes usados por outros com riscos baixos

- Otimização do processo para aumentar a economia atómica (condições estequiométricas ou quase estequiométricas)

- Otimização do processo do ponto de vista energético, procurando a realização a pressão e temperatura ambientais

-Utilização de reagentes catalíticos com riscos baixos em vez de reagentes estequiométricos

- Não utilização de derivatizações

- Substituir as substâncias não degradáveis por outras degradáveis, com os produtos de degradação inócuos

- Substituir as substâncias não renováveis por outras renováveis

descritas anteriormente $\left.{ }^{3,12,13}\right)$, estas últimas apresentadas e discutidas no material suplementar.

Para as sínteses do tris(acetilacetonato) de ferro(III) usaram-se os resultados referentes a um conjunto de experiências realizadas em laboratório em que foi preparado tris(acetilacetonato) de ferro(III) a partir do cloreto de ferro(III) hexaidratado e da acetilacetona (procedimento A), usando-se acetato de sódio como tampão. Utilizou-se inicialmente um grande excesso de ligando, mas a experiência foi otimizada para aumentar a verdura mediante a procura de proporções 
Tabela 5. Matrizes Verdes para as sínteses do tris(acetilacetonato) de ferro(III)

\begin{tabular}{ll}
\hline \multicolumn{2}{c}{$\begin{array}{c}\text { Procedimento A } \\
\text { 55\% de excesso de acetilacetona }\end{array}$} \\
\hline \multicolumn{1}{c}{ Pontos Fortes } & \multicolumn{1}{c}{ Pontos Fracos } \\
\hline 5 - Substâncias auxiliares com riscos & 1 - Formação de resíduos com riscos \\
baixos para a saúde e para o ambiente & moderados para a saúde, acetilace- \\
(acetato de sódio) & tona (Xn) \\
6 - Pressão e temperatura ambientais & 2 - Grande excesso de acetilacetona e \\
8 - Não se usam derivatizações & formação de coprodutos \\
9 - Não são necessários catalisadores & 3 - Riscos elevados para a saúde \\
& das substâncias envolvidas, $\mathrm{FeCl}_{3}$. \\
& $6 \mathrm{H}_{2} \mathrm{O}(\mathrm{C})$ \\
& $7-$ Nenhum dos reagentes $/ \mathrm{matérias}$ \\
& primas é renovável \\
& $10-$ Pelo menos uma das substâncias \\
& não é degradável em produtos inócuos \\
& $12-$ Riscos elevados de acidente \\
das substâncias envolvidas, $\mathrm{FeCl}_{3}$. & $6 \mathrm{H}_{2} \mathrm{O}(\mathrm{C})$
\end{tabular}

Procedimento B

$62 \%$ de excesso de acetilacetona

\begin{abstract}
5 - Substâncias auxiliares com riscos 1 - Formação de resíduos com riscos baixos para a saúde e para o ambiente

8 - Não se usam derivatizações
\end{abstract}

\begin{tabular}{ll}
\multicolumn{1}{c}{ Pontos Fortes } & \multicolumn{1}{c}{ Pontos Fracos } \\
\hline 5 - Substâncias auxiliares com riscos & 1 - Formação de resíduos com riscos \\
baixos para a saúde e para o ambiente & moderados para a saúde, acetilacetona \\
(acetato de sódio) & $($ Xn) \\
6 - Pressão e temperatura ambientais & 2 - Grande excesso de acetilacetona e \\
8 - Não se usam derivatizações & formação de coprodutos \\
9 - Não são necessários catalisadores & 3 - Riscos moderados para a saúde \\
& das substâncias envolvidas, acetila- \\
& cetona (Xn) e (tris)acetilacetonato de \\
& ferro(III) (Xn) \\
& 7 - Nenhum dos reagentes/matérias \\
& primas é renovável \\
& 10 - Pelo menos uma das substâncias \\
& não é degradável em produtos inócuos \\
& 12 - Riscos moderados de acidente \\
& das substâncias envolvidas, acetila- \\
& cetona (Xn) e (tris)acetilacetonato de \\
& ferro(III) (Xn)
\end{tabular}

Oportunidades

Ameaças

Realização em condições estequio-

- Substituição dos reagentes com riscos moderados/elevados por outros

- Utilização de reagentes renováveis \begin{tabular}{lll}
\hline - Realização em condições estequio- & - É difícil substituir os reagentes que \\
métricas & $\begin{array}{l}\text { Realização em colvem riscos moderados/elevados } \\
\text { métricas }\end{array}$ \\
- Substituição dos reagentes com riscos & por outros com riscos baixos & - Substituição dor \\
moderados/elevados por outros com & - É difícil substituir os reagentes por & riscos moderados/el \\
riscos baixos & outros renováveis e/ou degradáveis & com riscos baixos \\
- Utilização de reagentes renováveis e/ & & - Utilização de reag \\
ou degradáveis & & e/ou degradáveis \\
\hline
\end{tabular}

\begin{tabular}{lll}
\hline - Realização em condições estequio- & - É difícil substituir os reagentes que & Realização em conc \\
métricas & envolvem riscos moderados/elevados & métricas \\
- Substituição dos reagentes com riscos & por outros com riscos baixos & - Substituição dos \\
moderados/elevados por outros com & - É difícil substituir os reagentes por & riscos moderados/ \\
riscos baixos & outros renováveis e/ou degradáveis & com riscos baixos \\
- Utilização de reagentes renováveis e/ & & - Utilização de re \\
ou degradáveis & & e/ou degradáveis \\
\hline
\end{tabular}

\begin{tabular}{lll}
\hline - Realização em condições estequio- & - É difícil substituir os reagentes que \\
métricas & $\begin{array}{l}\text { Realização em colvem riscos moderados/elevados } \\
\text { métricas }\end{array}$ \\
- Substituição dos reagentes com riscos & por outros com riscos baixos & - Substituição dor \\
moderados/elevados por outros com & - É difícil substituir os reagentes por & riscos moderados/el \\
riscos baixos & outros renováveis e/ou degradáveis & com riscos baixos \\
- Utilização de reagentes renováveis e/ & & - Utilização de reag \\
ou degradáveis & & e/ou degradáveis \\
\hline
\end{tabular}

$\mathbf{7 \%}$ de excesso de acetilacetona

Alterações: realização em condições quase estequiométricas, os pontos fortes aumentam devido à alteração introduzida: $\mathbf{3 \%}$ de excesso de acetilacetona

Alterações: realização em condições quase estequiométricas, os pontos fortes aumentam devido à alteração introduzida:
1 - Resíduos de riscos baixos, porque não se considera acetilacetona nos resíduos 1 - Resíduos de riscos baixos, porque não se considera acetilacetona nos resíduos

próximas das estequiométricas. Para além disso, o cloreto de ferro(III) foi substituído por um reagente mais benigno, citrato de ferro(III) (procedimento B). As MV são apresentadas na Tabela 5 e os CV, em conjunto com as EV, nas Figuras 2a e 2b.

A aplicação dos critérios definidos para avaliação do cumprimento dos 12 princípios da QV, através das MV e dos CV, indica o cumprimento dos princípios P5, P6, P8 e P9 para as sínteses (processos A e B) realizadas com grande excesso de acetilacetona.

As MV apresentam quatro pontos fortes (correspondentes ao cumprimento desses princípios) e é identificada a realização em

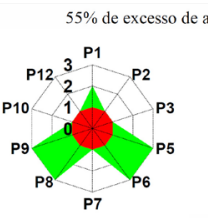

IPE $=32,50$

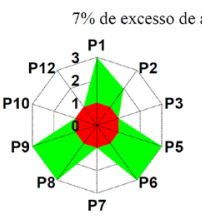

IPE $=40,00$

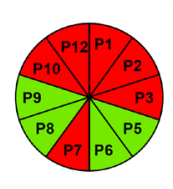

ICP $=40,00$

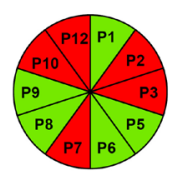

ICP $=50,00$

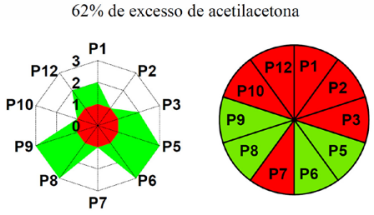

IPE $=41,25$ $\mathrm{ICP}=40,00$

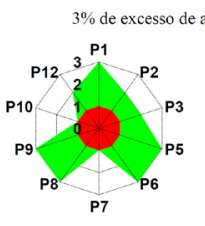

$\operatorname{IPE}=51,25$ condições próximas da estequiometria como uma das oportunidades para aumentar o número de princípios cumpridos. O procedimento em condições quase estequiométricas levou à eliminação do ponto fraco 1 (o risco para a saúde dos resíduos formados baixou, pois a acetilacetona $(\mathrm{Xn})$ deixou de ser considerada nos resíduos) e ao cumprimento de mais um princípio $(\mathrm{P} 1)$.

Os CV tornaram-se mais verdes e mostram que a percentagem de princípios cumpridos passou de 40 para $50 \%$ (aliás estes valores coincidem, como seria de esperar, com as percentagens de pontos fortes para cada caso).

Estas análises (MV e CV) não permitiram distinguir os procedimentos $\mathrm{A}$ e $\mathrm{B}$, mas a $\mathrm{EV}$ indica que houve aumento de verdura no procedimento B (Figuras 2a e 2b), já que aumenta a área verde, como indicam os valores de IPE (percentagem de área verde da estrela relativamente à área de uma estrela de verdura máxima). Em condições de grande excesso de acetilacetona IPE aumenta de 32,50 para $41,25 \%$ e em condições quase estequiométricas, de 40,00 para $51,25 \%$. Ao contrário da MV e do CV, a EV é sensível à substituição do cloreto de ferro(III) pelo citrato de ferro(III), o que aumenta o grau de cumprimento dos princípios P3 e P12 de 1 para 2.

As sínteses dos (bis)acetilacetonatos de manganés(II) e de cálcio foram também realizadas em condições de um grande excesso de ligando e em proporções próximas das estequiométricas. As MV os CV (em conjunto com as EV) são apresentados na Tabela $1 \mathrm{~S}$ e na Figura 1S, material suplementar, respectivamente. Neste caso, verificou-se que os $\mathrm{MV}$ e CV permitiram identificar a maior verdura da síntese do composto de cálcio, bem como o aumento da verdura quando em proporções próximas das estequiométricas, embora só a
Figura 2. a) Estrelas e Círculos Verdes para as sínteses do tris(acetilacetonato) de ferro(III), Procedimento A; b) Estrelas e Círculos Verdes para as sínteses do tris(acetilacetonato) de ferro(III), Procedimento $B$ 
EV tenha permitido identificar princípios parcialmente cumpridos (informações detalhadas no material suplementar).

\section{DISCUSSÃO}

Comparam-se a seguir as novas métricas apresentadas entre si e com a EV.

\section{Comparação da matriz verde com o círculo verde}

A MV permite identificar os princípios que são cumpridos, bem como os aspetos que levam a esse cumprimento, e evidencia como atuar para melhorar a verdura e os aspetos que tornam difícil esse melhoramento - oportunidades e ameaças, respetivamente. Quando se exprime o resultado pelo CV perde-se a informação que levou à sua construção, no entanto esta ferramenta permite identificar rapidamente quais os princípios que são cumpridos. A MV e o CV usam ambos os mesmos critérios de cumprimento dos princípios e são complementares: o CV dá uma imagem do cumprimento dos princípios e a MV, mais analítica, ajuda a uma atitude proativa já que permite identificar quais os aspetos a melhorar para aumentar o número de princípios cumpridos. $\mathrm{O} \mathrm{CV}$ pode assim ser considerado como uma representação gráfica da MV.

\section{Comparação da matriz verde com a estrela verde}

A EV, tal como a MV, permite identificar os princípios que são ou não cumpridos, mas envolve uma análise mais profunda, com três níveis de cumprimento, o que a torna sensível a alterações que levem a um cumprimento parcial dos princípios, mas implica uma construção mais complexa. As tabelas que têm que ser construídas para o efeito apresentam, com pormenor, os aspetos que levaram às decisões sobre o cumprimento dos diversos princípios, sendo assim possível identificar aqueles em que se pode atuar para melhorar a verdura. Por outro lado, consiste em uma representação gráfica, o que permite identificar visualmente o grau de cumprimento de cada um dos princípios avaliados.

\section{Comparação do círculo verde com a estrela verde}

De acordo com os critérios estabelecidos, verificou-se que quando se compara a verdura avaliada pelo $\mathrm{CV}$ com a $\mathrm{EV}$, os princípios cumpridos correspondem aos princípios pontuados com 3 na EV. Os princípios que são parcialmente cumpridos aparecem nos CV como não cumpridos, mas com pontuações 1 ou 2 na EV. Estas diferenças devem-se a que os critérios definidos para o cumprimento dos princípios nos CV são do tipo binário - cumprimento/não cumprimento de cada princípio, enquanto para as EV existe mais um nível de cumprimento dos princípios ${ }^{1-3}$ (Tabelas $2 \mathrm{~S}$ e 3S, material suplementar), daí a EV permitir uma avaliação mais rigorosa, mas requer mais trabalho.

\section{CONCLUSÕES}

$\mathrm{O} \mathrm{CV}$ e a MV, atendendo à facilidade de construção que resulta de os critérios de cumprimento dos princípios envolverem só dois níveis, são úteis para uma avaliação prévia da verdura de uma reação química/processo, permitindo identificar aspetos a alterar nas reacções de síntese e os efeitos dessas alterações na verdura, sem ser necessário realizar as experiências. Estas novas métricas completam-se, já que o CV permite uma identificação rápida e visual dos princípios cumpridos e a MV permite identificar alterações possíveis para aumentar a verdura. No entanto, não são sensíveis a todos os melhoramentos que possam ser introduzidos, pois não permitem identificar diferentes graus de cumprimento dos princípios. Estas novas métricas são úteis, em particular, para o ensino da QV a nível mais elementar, permitindo familiarizar os alunos com os 12 princípios da QV, bem como com métricas holísticas e o reconhecimento da sua utilidade e importância.

A utilização de métricas holísticas é fundamental para a avaliação da verdura de reações e processos químicos e a sua utilização no ensino da química apresenta diversas vantagens: permite criar facilmente situações de utilização dos princípios da QV, aprofundando a sua compreensão; dá uma visão da necessidade de usar abordagens holísticas na prática da QV e de utilização de instrumentos que permitam a confirmação de um aumento global da verdura, quando se fazem alterações com essa intenção e, ajuda a interiorizar na mente dos alunos uma atitude proativa para facilitar a transformação da Química numa QV e sustentável. As métricas CV e MV apresentadas permitem cumprir estes objectivos, com a vantagem de poderem ser usadas com facilidade numa grande variedade de situações, por serem muito simples.

\section{MATERIAL SUPLEMENTAR}

Está disponível em http://quimicanova.sbq.org.br, na forma de arquivo PDF, com acesso livre. Inclui a descrição e avaliação da verdura das sínteses dos (bis)acetilacetonatos de manganés(II) e de cálcio utilizando as métricas apresentadas (Tabela 1S, Figura 1S) e as Tabelas $2 \mathrm{~S}$ e $3 \mathrm{~S}$, que apresentam as componentes e as pontuações necessárias à construção das EV.

\section{AGRADECIMENTOS}

À colaboração na realização das sínteses da aluna estagiária para professora do Ensino Secundário, O. M. S. Martins. O trabalho de M. G. T. C. Ribeiro foi suportado pela Fundação para a Ciência e a Tecnologia através da bolsa PEst-C/EQB/LA0006/2011.

\section{REFERÊNCIAS}

1 Ribeiro, M. G. T. C.; Costa, D.A.; Machado, A. A. S. C.; Quim. Nova 2010, 33, 759 .

2. Ribeiro, M. G. T. C.; Costa, D. A.; Machado, A. A. S. C.; Green Chem. Lett. Rev. 2010, 3, 149.

3. Ribeiro, M. G. T. C.; Machado, A. A. S. C.; J. Chem. Educ. 2011, 88, 947.

4. Frosch, R. A.; Industrial Environmental Performance Metrics Challenges and Opportunities, National Academy Press: Washington, 1999.

5. Allen, D. T.; Shonnard, D. R.; Green Engineering - Environmentally Conscious Design of Chemical Processes, Prentice-Hall: Upper Saddle River, 2002.

6. Anastas, P. T.; Warner, J. C.; Green Chemistry - Theory and Practice, Oxford Press: Oxford, 1998.

7. Costa, D. A.; Ribeiro, M. G. T. C.; Machado, A. A. S. C.; Química - Bol. S. P. Q. 2009, 115, 41 .

8. Costa, D. A.; Ribeiro, M. G. T. C.; Machado, A. A. S. C.; Química - Bol. S. P. Q. 2011, 123, 63 .

9. Deetlefs, M.; Seddon, K. R.; Green Chem. 2010, 12, 17.

10. Jackson, S. E.; Joshi, A.; Erhardt, N. L.; J. Manage. 2003, 29, 801.

11. Sin, G.; van Hulle, S. W. H.; De Pauw, D. J. W.; van Griensven, A.; Vanrolleghem, P. A.; Water Res. 2005, 39, 2459.

12. Szfran, Z.; Pike, R. M.; Foster, J. C.; Microscale General Chemistry Laboratory with Selected Macroscale Experiments, John Willey \& Sons: New York, 2003.

13. Charles, R. G.; Pawlikowski, M. A.; J. Phys. Chem. 1958, 62, 440 


\section{NOVAS MÉTRICAS HOLÍSTICAS PARA AVALIAÇÃO DA VERDURA DE REAÇÕES DE SÍNTESE EM LABORATÓRIO}

\author{
Maria Gabriela T. C. Ribeiro* \\ 687, Porto 4169-007, Portugal \\ Adélio A. S. C. Machado \\ 4169-007, Portugal

\section{Avaliação da verdura das sínteses dos (bis)acetilacetonatos de manganés(II) e de cálcio}

REQUIMTE, Departamento de Química e Bioquímica, Faculdade de Ciências, Universidade do Porto, Rua do Campo Alegre,

Departamento de Química e Bioquímica, Faculdade de Ciências, Universidade do Porto, Rua do Campo Alegre, 687, Porto

\section{Síntese dos compostos}

Usaram-se os resultados referentes a um conjunto de experiências de síntese de bis(acetilacetonatos) de catiões bivalentes realizadas anteriormente em laboratório. ${ }^{1,2} \mathrm{O}$ acetilacetonato de manganés(II) foi preparado a partir do cloreto de manganés(II) tetraidratado, a que se juntou acetilacetona (excesso de 66\%); utilizou-se hidróxido de sódio para aumentar o $\mathrm{pH}$ da mistura reacional. O bis(acetilacetonato) de cálcio foi preparado a partir do hidróxido de cálcio e de acetilacetona (excesso de 60\%), sem adição de hidróxido de sódio. Para aumentar a verdura, as sínteses foram otimizadas procurando-se proporções próximas das estequiométricas (obtidas para excesso de 7\%).
Círculos verdes (CV) e matrizes verdes (MV)

As MV apresentam-se na Tabela $1 \mathrm{~S}$ e os CV, em conjunto com as EV, na Figura 1S.

\section{DISCUSSÃO}

As MV (análises SWOT) das sínteses dos bis(acetilacetonatos) de manganés(II) e de cálcio, realizadas com grande excesso acetilacetona, mostram que a do composto de cálcio é mais verde. Indicam também, como oportunidade para melhorar o cumprimento dos princípios, a realização das sínteses em condições próximas das estequiométricas, o que levou à diminuição dos pontos fracos. $\mathrm{O} C \mathrm{~V}$ tornou-se mais verde, passando a ser cumpridos 4 princípios em vez de 3 no caso do bis(acetilacetonato) de manganés(II) e 6 em vez de

Tabela 1S. Matrizes Verdes para as sínteses dos bis(acetilacetonatos) de manganés(II) e de cálcio

\begin{tabular}{|c|c|c|c|}
\hline \multicolumn{2}{|c|}{$\begin{array}{l}\text { Bis(acetilacetonato) de manganés(II) } \\
66 \% \text { de excesso de acetilacetona }\end{array}$} & \multicolumn{2}{|c|}{$\begin{array}{l}\text { Bis(acetilacetonato) de cálcio } \\
66 \% \text { de excesso de acetilacetona }\end{array}$} \\
\hline Pontos Fortes & Pontos Fracos & Pontos Fortes & Pontos Fracos \\
\hline $\begin{array}{l}6 \text { - Pressão e temperatura ambientais } \\
8 \text { - Não se usam derivatizações } \\
9 \text { - Não são necessários catalisadores }\end{array}$ & $\begin{array}{l}1 \text { - Formação de resíduos com riscos } \\
\text { moderados para a saúde, acetilace- } \\
\text { tona (Xn) } \\
2 \text { - Grande excesso de acetilacetona e } \\
\text { formação de coprodutos } \\
3 \text { - Risco elevado para a saúde das } \\
\text { substâncias envolvidas, KOH (C) } \\
5 \text { - Substâncias auxiliares com riscos } \\
\text { elevados para saúde KOH (C) } \\
7 \text { - Nenhum dos reagentes/matérias } \\
\text { primas é renovável } \\
10 \text { - Pelo menos uma das substâncias } \\
\text { não é degradável em produtos inócuos } \\
12 \text { - Riscos elevados de acidente das }\end{array}$ & $\begin{array}{l}5 \text { - Substâncias auxiliares com riscos } \\
\text { baixos para a saúde e para o ambiente } \\
\text { (só se utiliza água) } \\
6 \text { - Pressão e temperatura ambientais } \\
8 \text { - Não se usam derivatizações } \\
9 \text { - Não são necessários catalisadores }\end{array}$ & $\begin{array}{l}1 \text { - Formação de resíduos com riscos } \\
\text { moderados para a saúde, acetilacetona } \\
\text { (Xn) } \\
2 \text { - Grande excesso de acetilacetona } \\
3 \text { - Riscos moderados para a saúde das } \\
\text { substâncias envolvidas, acetilacetona } \\
\text { (Xn) e acetilacetonato de cálcio (Xn) } \\
7 \text { - Nenhum dos reagentes/matérias } \\
\text { primas é renovável } \\
10 \text { - Pelo menos uma das substâncias } \\
\text { não é degradável em produtos inócuos } \\
12 \text { - Riscos moderados de acidente das } \\
\text { substâncias envolvidas, acetilacetona } \\
\text { (Xn) e acetilacetonato de cálcio (Xn) }\end{array}$ \\
\hline
\end{tabular}

\begin{tabular}{|c|c|c|c|}
\hline Oportunidades & Ameaças & Oportunidades & Ameaças \\
\hline $\begin{array}{l}\text { - Realização em condições estequio- } \\
\text { métricas } \\
\text { - Substituição dos reagentes com riscos } \\
\text { moderados/elevados por outros com } \\
\text { riscos baixos } \\
\text { - Utilização de reagentes renováveis e/ } \\
\text { ou degradáveis }\end{array}$ & $\begin{array}{l}\text { - É difícil substituir os reagentes que } \\
\text { envolvem riscos moderados/elevados } \\
\text { por outros com riscos baixos } \\
\text { - É difícil substituir os reagentes por } \\
\text { outros renováveis e/ou degradáveis }\end{array}$ & $\begin{array}{l}\text { - Realização em condições estequio- } \\
\text { métricas } \\
\text { - Substituição dos reagentes com } \\
\text { riscos moderados/elevados por outros } \\
\text { com riscos baixos } \\
\text { - Utilização de reagentes renováveis } \\
\text { e/ou degradáveis }\end{array}$ & $\begin{array}{l}\text { - É difícil substituir os reagentes que } \\
\text { envolvem riscos moderados/elevados } \\
\text { por outros com riscos baixos } \\
\text { - É difícil substituir os reagentes por } \\
\text { outros renováveis e/ou degradáveis }\end{array}$ \\
\hline \multicolumn{2}{|c|}{$7 \%$ de excesso de acetilacetona } & \multicolumn{2}{|c|}{$7 \%$ de excesso de acetilacetona } \\
\hline \multicolumn{2}{|c|}{$\begin{array}{l}\text { Alterações: realização em condições quase estequiométricas, } \\
\text { os pontos fortes aumentam devido à alteração introduzida: } \\
1 \text { - Resíduos de riscos baixos, porque não se considera a acetilacetona nos } \\
\text { resíduos }\end{array}$} & \multicolumn{2}{|c|}{$\begin{array}{l}\text { Alterações: realização em condições quase estequiométricas, } \\
\text { os pontos fortes aumentam devido à alteração introduzida: } \\
1 \text { - Resíduos de riscos baixos, porque não se considera a acetilacetona nos } \\
\text { resíduos } \\
2 \text { - Condições quase estequiométricas sem formação de coprodutos }\end{array}$} \\
\hline
\end{tabular}

*e-mail: gribeiro@fc.up.pt 


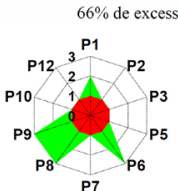

IPE $=22,50$

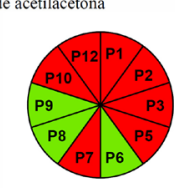

$\mathrm{IPE}=30,00$

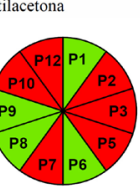

$\mathrm{ICP}=40,00$

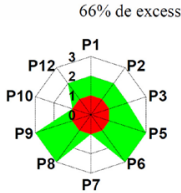

IPE $=46,25$

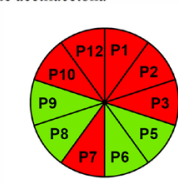

ICP $=40,00$

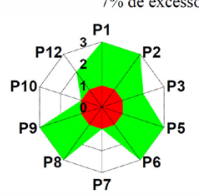

$\operatorname{IPE}=57,50$

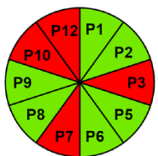

$\mathrm{ICP}=60,00$
Figura 1S. Estrelas e Círculos Verdes para as sínteses do bis(acetilacetonato) de manganês(II) (A) e do bis(acetilacetonato) de cálcio (B)

4 no caso do bis(acetilacetonato) de cálcio. Neste último caso, como não há formação de coprodutos para além da água, ao reduzir-se o excesso de acetilacetona para proporções próximas das estequiométricas, o princípio 2 passa a ser cumprido. Os CV mostram que a percentagem de princípios cumpridos aumentou de 30 para $40 \%$ no caso do bis(acetilacetonato) de manganês(II) e de 40 para $60 \%$ no caso do bis(acetilacetonato) de cálcio. A EV permite ainda identificar os princípios que são parcialmente cumpridos, a que corresponde a pontuação de 2, como no caso do princípio P2, para o bis(acetilacetonato) de manganês(II) (Figura 1SA) em condições quase estequiométricas, e dos princípios P2, P3 e P12 (Figura 1S), quando se comparam as sínteses dos bis(acetilacetonatos) de manganês(II) e de cálcio, com grande excesso de acetilacetona.

Nas Tabelas 2S e 3S apresentam-se as informações necessárias para a construção das EV. Para informação mais detalhada consultar ref. 1.

\section{REFERÊNCIAS}

1. Ribeiro, M. G. T. C.; Machado, A. A. S. C.; J. Chem. Educ. 2011, 88 , 947.

2. Charles, R. G.; Pawlikowski, M. A.; J. Phys. Chem. 1958, 62, 440.
Tabela 2S. Critérios para a classificação das substâncias para construção das EV

\begin{tabular}{|c|c|c|}
\hline Riscos & Símbolos de risco & Pontuação \\
\hline \multirow[t]{6}{*}{ Saúde } & $\mathrm{C}-$ corrosivo & 3 \\
\hline & $\mathrm{T}$ - tóxico & \\
\hline & $\mathrm{T}+-$ muito tóxico & \\
\hline & $\mathrm{Xn}$ - prejudicial & 2 \\
\hline & $\mathrm{Xi}$ - irritante & \\
\hline & Nenhuma indicação & 1 \\
\hline \multirow[t]{2}{*}{ Ambiente } & $\mathrm{N}$ - perigoso para o ambiente & 3 \\
\hline & Nenhuma indicação & 1 \\
\hline \multicolumn{3}{|c|}{ b) Riscos de acidente das substâncias envolvidas } \\
\hline Riscos & Símbolos de risco & Pontuação \\
\hline \multirow[t]{6}{*}{ Saúde } & $\mathrm{C}$ - corrosivo & 3 \\
\hline & $\mathrm{T}$ - tóxico & \\
\hline & $\mathrm{T}+-$ muito tóxico & \\
\hline & $\mathrm{Xi}$ - irritante & 2 \\
\hline & $\mathrm{Xn}$ - prejudicial & \\
\hline & Nenhuma indicação & 1 \\
\hline \multirow[t]{3}{*}{ Inflamabilidade } & F - muito inflamável & 3 \\
\hline & $\mathrm{F}+-$ extremanente inflamáve & \\
\hline & Nenhuma indicação & 1 \\
\hline \multirow[t]{3}{*}{ Reatividade } & E - explosivo & 3 \\
\hline & $\mathrm{O}$ - agente oxidante & 3 \\
\hline & Nenhuma indicação & 1 \\
\hline \multicolumn{3}{|c|}{ c) Degradabilidade e renovabilidade das substâncias envolvidas } \\
\hline Características & Critérios & Pontuação \\
\hline \multirow[t]{3}{*}{ Degradabilidade } & $\begin{array}{l}\text { Não degradáveis ou que não possam } \\
\text { ser tratados para se obter a sua de- } \\
\text { gradação em produtos de degradação } \\
\text { inócuos }\end{array}$ & 3 \\
\hline & $\begin{array}{l}\text { Possam ser tratadas para obter de- } \\
\text { gradação com produtos de degrada- } \\
\text { ção inócuos }\end{array}$ & 2 \\
\hline & $\begin{array}{l}\text { Degradáveis com produtos de de- } \\
\text { gradação inócuos }\end{array}$ & 1 \\
\hline \multirow[t]{2}{*}{ Renovabilidade } & Não renováveis & 3 \\
\hline & Renováveis & 1 \\
\hline
\end{tabular}


Tabela 3S. Componentes e pontuações para construção das EV ( $\mathrm{p}$ = pontuação)

\begin{tabular}{|c|c|c|}
\hline Princípio da QV & Critérios & $\mathrm{p}$ \\
\hline \multirow[t]{3}{*}{ P1 - Prevenção } & Todos os resíduos são inócuos (p=1, Tabela 2Sa) & 3 \\
\hline & $\begin{array}{l}\text { Resíduos que envolvam um risco moderado para a saúde e ambiente ( } \mathrm{p}=2 \text {, Tabela } 2 \mathrm{Sa} \text {, pelo menos para uma } \\
\text { substância, sem substâncias com } \mathrm{p}=3 \text { ) }\end{array}$ & 2 \\
\hline & Formação de pelo menos um resíduo que envolva um risco elevado para a saúde e ambiente ( $\mathrm{p}=3$, Tabela 2Sa) & 1 \\
\hline \multirow[t]{4}{*}{ P2- Economia atómica } & Reações sem reagentes em excesso $(\leq 10 \%)$ e sem formação de coprodutos & 3 \\
\hline & Reações sem reagentes em excesso $(\leq 10 \%)$ e com formação de coprodutos & 2 \\
\hline & Reações com reagentes em excesso (>10\%) e sem formação de coprodutos & 2 \\
\hline & Reações com reagentes em excesso (>10\%) e com formação de coprodutos & 1 \\
\hline \multirow{3}{*}{$\begin{array}{l}\text { P3 - Sínteses menos peri- } \\
\text { gosas }\end{array}$} & Todas as substâncias envolvidas são inócuas ( $\mathrm{p}=1$, Tabela 1a) & 3 \\
\hline & $\begin{array}{l}\text { As substâncias envolvidas apresentam um risco moderado para a saúde e ambiente ( } \mathrm{p}=2 \text {, Tabela } 2 \text { Sa, pelo menos } \\
\text { para uma substância, sem substâncias com } \mathrm{p}=3 \text { ) }\end{array}$ & 2 \\
\hline & Pelo menos uma das substâncias envolvidas apresenta um risco elevado para a saúde e ambiente ( $\mathrm{p}=3$, Tabela 2Sa) & 1 \\
\hline \multirow{3}{*}{$\begin{array}{l}\text { P5 - Solventes e outras } \\
\text { substâncias auxiliares mais } \\
\text { seguras }\end{array}$} & Os solventes e as substâncias auxiliares não existem ou são inócuas ( $\mathrm{p}=1$, Tabela 2Sa) & 3 \\
\hline & $\begin{array}{l}\text { Os solventes e as substâncias auxiliares usadas envolvem um risco moderado para a saúde e ambiente ( } \mathrm{p}=2 \text {, Tabela } \\
2 \mathrm{Sa} \text {, pelo menos para uma substância, sem substâncias com } \mathrm{p}=3 \text { ) }\end{array}$ & 2 \\
\hline & $\begin{array}{l}\text { Pelo menos um dos solventes ou uma das substâncias auxiliares usadas envolve um risco elevado para a saúde e } \\
\text { ambiente ( } \mathrm{p}=3 \text {, Tabela } 2 \mathrm{Sa} \text { ) }\end{array}$ & 1 \\
\hline \multirow{3}{*}{$\begin{array}{l}\text { P6 - Planificação para conse- } \\
\text { guir eficácia energética }\end{array}$} & Temperatura e pressão ambientais & 3 \\
\hline & Pressão ambiental e temperatura entre $0^{\circ} \mathrm{C}$ e $100^{\circ} \mathrm{C}$ que implique arrefecimento ou aquecimento & 2 \\
\hline & Pressão diferente da ambiental e/ou temperatura muito afastada da ambiental & 1 \\
\hline \multirow{3}{*}{$\begin{array}{l}\text { P7 - Uso de matérias primas } \\
\text { renováveis }\end{array}$} & Todos os reagentes/matérias-primas envolvidos são renováveis ( $\mathrm{p}=1$, Tabela $2 \mathrm{Sc}$ ) & 3 \\
\hline & Pelo menos um dos reagentes/matérias-primas envolvidos é renovável, não se considera a água ( $\mathrm{p}=1$, Tabela $2 \mathrm{Sc}$ ) & 2 \\
\hline & Nenhum dos reagentes/matérias-primas envolvidos é renovável, não se considera a água ( $\mathrm{p}=3$, Tabela $2 \mathrm{Sc}$ ) & 1 \\
\hline \multirow{3}{*}{$\begin{array}{l}\text { P8 - Redução de derivati- } \\
\text { zações }\end{array}$} & Não se usam derivatizações & 3 \\
\hline & Usa-se apenas uma derivatização ou operação semelhante & 2 \\
\hline & Usam-se várias derivatizações ou operações semelhantes & 1 \\
\hline \multirow[t]{3}{*}{ P9 - Catalisadores } & Catalisadores não necessários ou os catalisadores são inócuos (p=1, Tabela 2Sa) & 3 \\
\hline & Utilizam-se catalisadores que envolvem um risco moderado para a saúde e ambiente ( $\mathrm{p}=2$, Tabela $2 \mathrm{Sa}$ ) & 2 \\
\hline & Utilizam catalisadores que envolvem um risco elevado para a saúde e ambiente ( $\mathrm{p}=3$, Tabela $2 \mathrm{Sa}$ ) & 1 \\
\hline \multirow{3}{*}{$\begin{array}{l}\text { P10 - Planificação para a } \\
\text { degradação }\end{array}$} & Todas as substâncias envolvidas são degradáveis com os produtos de degradação inócuos ( $\mathrm{p}=1$, Tabela 2Sc) & 3 \\
\hline & $\begin{array}{l}\text { Todas as substâncias envolvidas que não são degradáveis podem ser tratados para obter a sua degradação com os } \\
\text { produtos de degradação inócuos ( } \mathrm{p}=2 \text {, Tabela } 2 \mathrm{Sc} \text { ) }\end{array}$ & 2 \\
\hline & $\begin{array}{l}\text { Pelo menos uma das substâncias envolvidas não é degradável nem pode ser tratado para obter a sua degradação } \\
\text { com produtos de degradação inócuos ( } \mathrm{p}=3 \text {, Tabela } 2 \mathrm{Sc} \text { ) }\end{array}$ & 1 \\
\hline \multirow{3}{*}{$\begin{array}{l}\text { P12 - Química inerentemente } \\
\text { mais segura quanto à preven- } \\
\text { ção de acidentes }\end{array}$} & As substâncias envolvidas apresentam um baixo risco de acidente químico ( $\mathrm{p}=1$, Tabela $2 \mathrm{Sb}$ ) & 3 \\
\hline & $\begin{array}{l}\text { As substâncias envolvidas apresentam um risco moderado de acidente químico(p=2, Tabela } 2 \mathrm{Sb} \text {, pelo menos para } \\
\text { uma substância, sem substâncias com } \mathrm{p}=3 \text { ) }\end{array}$ & 2 \\
\hline & As substâncias envolvidas apresentam um risco elevado de acidente químico ( $\mathrm{p}=3$, Tabela $2 \mathrm{Sb}$ ) & 1 \\
\hline
\end{tabular}

